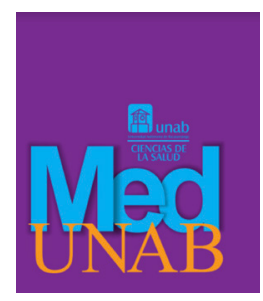

REVISTA DE LA FACULTAD

DE CIENCIAS DE LA SALUD

\title{
Hidrocele como manifestación inicial de tuberculosis genitourinaria y miliar
}

Hydrocele as initial manifestation of genitourinary and miliary tuberculosis

Hidrocele como manifestação inicial da tuberculose geniturinária e miliar

\section{Juliana Álvarez-Jaramillo, MD. ${ }^{1}$, Ana María Ortiz-Zableh, MD. ${ }^{2}$, Pamela} Tarazona-Jiménez, MD. ${ }^{3}$, Alfredo Ortiz-Azuero, MD., Esp. ${ }^{4}$

1. Médica, Residente Urología segundo año, Universidad Autónoma de Bucaramanga, Floridablanca, Santander, Colombia.

2. Médica y Cirujana, Residente de Urología primer año, Universidad Autónoma de Bucaramanga, Floridablanca, Santander, Colombia.

3. Médica, en servicio social obligatorio, Universidad Autónoma de Bucaramanga, Floridablanca, Santander, Colombia.

4. Médico y cirujano, Urólogo, Docente de postgrado de Urología, Universidad Autónoma de Bucaramanga, Floridablanca, Santander, Colombia

Correspondencia: Pamela Alejandra Tarazona Jiménez. Médica, en servicio social obligatorio, Universidad Autónoma de Bucaramanga. Calle 21 \#25-27 apto 403, Bucaramanga, Santander. E-mail: ptarazona@unab.edu.co

Cómo citar: Álvarez-Jaramillo J, Ortiz-Zableh AM, Tarazona-Jiménez P, Ortiz-Azuero A. Hidrocele como manifestación inicial de tuberculosis genitourinaria y miliar. MedUNAB. 2019;22(1):71-78. doi:10.29375/01237047.3534

\section{INFORMACIÓN ARTÍCULO}

Artículo recibido: 05 de marzo de 2019

Artículo aceptado: 01 de junio de 2019

DOI: https://doi.org/10.29375/01237047.3534

\section{RESUMEN}

Introducción. La tuberculosis es una enfermedad infectocontagiosa que puede afectar cualquier órgano del cuerpo, incluyendo el sistema genitourinario, representando el 33.7-45.5\% de las tuberculosis extrapulmonares. El objetivo de este trabajo es reportar el caso de un paciente con hidrocele como manifestación inicial de tuberculosis genitourinaria y miliar, enfermedad que no se sospechaba.

Presentación del caso. Paciente masculino previamente sano, que consulta a urgencias por orquialgia e hidrocele bilateral, con secreción purulenta por escroto, requiriendo manejo antibiótico intravenoso e hidrocelectomía derecha, con hallazgos 
intraoperatorios de engrosamiento del epidídimo derecho, y drenaje de material caseoso y purulento. Se realizó epididimectomía ipsilateral, se solicitaron pruebas de detección de bacilos tuberculosos en espécimen y derivado proteico purificado, que fueron positivas. En el postoperatorio presentó sintomatología respiratoria; paraclínicos evidenciaron compromiso pulmonar, pleural y de la vía urinaria por bacilos tuberculosos. Se inicia manejo antituberculoso con evolución satisfactoria.

Discusión. El genitourinario es considerado el segundo sistema con mayor afectación de tuberculosis extrapulmonar. El órgano más afectado es el riñón (en un $80 \%$ con respecto a los demás) y el órgano genital es el epidídimo (22 - $55 \%$ ). Debe sospecharse en pacientes con síntomas urinarios crónicos sin causa aparente. Se asocia a una alta tasa de morbimortalidad por infertilidad y falla renal.

Conclusiones. A pesar de su sintomatología inespecífica y de tratarse de una entidad poco sospechada, la tuberculosis genitourinaria debe descartarse al existir tuberculosis pulmonar. Su diagnóstico y tratamiento oportuno serán de gran importancia para evitar complicaciones secundarias.

Palabras clave:

Tuberculosis; Tuberculosis urogenital; Tuberculosis de los genitales masculinos; Tuberculosis renal; Epidídimo; Hidrocele testicular.

\section{ABSTRACT}

Introduction. Tuberculosis is an infectious disease that can affect any organ in the body, including the genitourinary system, which accounts for $33.7-45.5 \%$ of non-pulmonary tuberculosis cases. The purpose of this paper is to report a case of hydrocele as initial manifestation of genitourinary and miliary tuberculosis, which was an unsuspected disease.

Case Presentation. Previously healthy male patient is admitted to emergencies due to orchialgia and bilateral hydrocele, with purulent secretion from the scrotum. Was managed with intravenous antibiotic and right hydrocelectomy. Intraoperative findings of thickening of right epididymis and drainage of caseous and purulent material. Ipsilateral epididymectomy was performed; testing for detection of tubercle bacillus in specimen and purified protein derivative was requested, and was found positive. In the postoperative period, respiratory symptoms arose; paraclinical tests found compromised lungs, pleura and urinary tract by tubercle bacillus. Antituberculous treatment was initiated with satisfactory evolution.

Discussion. The genitourinary system is the second-most affected system by nonpulmonary tuberculosis. The most affected organ is the kidney (by $80 \%$ compared to the others) and the most affected genital organ is the epididymis (22-55\%). It should be suspected in patients with chronic urinary symptoms with no apparent cause. It is associated with a high rate of morbidity and mortality due to infertility and kidney failure.

Conclusions. Despite the non-specific symptoms and because it is not normally a suspected entity, genitourinary tuberculosis should be ruled out when pulmonary tuberculosis exists. Timely diagnosis and treatment are very important in order to prevent secondary complications.

Keywords:

Tuberculosis; Urogenital tuberculosis; Male genitalia Tuberculosis; Kidney tuberculosis; Epididymis; Testicular hydrocele.

\section{RESUMO}

Introdução. A tuberculose é uma doença infecciosa que pode afetar qualquer órgão do corpo, incluindo o sistema geniturinário, representando 33.7 a $45.5 \%$ da tuberculose extrapulmonar. O objetivo deste trabalho é relatar o caso de um paciente 
com hidrocele como uma manifestação inicial de tuberculose geniturinária e miliar, uma doença que não se suspeitava.

Apresentação do caso. Paciente do sexo masculino previamente saudável, que consultou a emergência para orquialgia e hidrocele bilateral, com secreção purulenta do escroto, necessitando de tratamento antibiótico endovenoso e hidrocelectomia direita, com achados intraoperatórios de espessamento do epidídimo direito e drenagem de material purulento e caseoso. Foi realizada uma epididimectomia ipsilateral e foram solicitados exames de bacilos tuberculosos em espécime e derivado proteico purificado, que foram positivos. No pós-operatório, apresentou sintomas respiratórios; testes para-clínicos mostraram comprometimento pulmonar, pleural e do trato urinário devido a bacilos da tuberculose. Começa-se o tratamento antituberculose com evolução satisfatória.

Discussão. O sistema geniturinário é considerado o segundo com maior comprometimento da tuberculose extrapulmonar. O órgão mais afetado é o rim $(80 \%$ em relação aos demais) e o órgão genital é o epidídimo (22 a 55 \%). Deve-se suspeitar em pacientes com sintomas urinários crônicos sem causa aparente. Está associada a uma alta taxa de morbimortalidade devido à infertilidade e insuficiência renal.

Conclusões. Apesar de sua sintomatologia inespecífica e de ser uma entidade pouco suspeitada, a tuberculose geniturinária deve ser descartada quando existir tuberculose pulmonar. Seu diagnóstico e tratamento oportuno serão de grande importância para evitar complicações secundárias.

Palavras-chave:

Tuberculose; Tuberculose urogenital; Tuberculose dos genitais masculinos; Tuberculose renal; Epidídimo; Hidrocele testicular

\section{Introducción}

Reconocida como "la gran imitadora", la tuberculosis (TBC) es una enfermedad infectocontagiosa que puede afectar cualquier órgano del cuerpo, incluyendo el sistema genitourinario (SGU) (1). Puede confundirse con un amplio espectro de patologías, por lo que se dificulta su oportuno diagnóstico y tratamiento.

La TBC continúa siendo una de las enfermedades infectocontagiosas con mayor impacto en salud pública. Es la novena causa de muerte a nivel mundial y la primera por enfermedades infecciosas, por encima del VIH-SIDA (2). Dentro de las formas extrapulmonares, la tuberculosis genitourinaria(TBCGU) representa del 33.7 $\%$ al $45.5 \%$ de los casos a nivel mundial. Generalmente causada por el Mycobacterium tuberculosis en el 80 - 90 \% de los casos. Sin embargo, el Mycobacterium bovis también es considerado un agente etiológico (3). Según cifras del Instituto Nacional de Salud, en el 2017 los casos de TBC extrapulmonar correspondieron al 6.6 $\%$ del total de casos diagnosticados (4). Se calcula que el $3.9 \%$ correspondieron a TBCGU (5).

Se presenta el caso de un paciente asintomático y previamente sano que consultó a urología por hidrocele $\mathrm{y}$ quien finalmente fue diagnosticado con TBC pulmonar, pleural y de la vía urinaria, con compromiso del epidídimo, próstata y uréteres, enfermedad que no se sospechaba y que constituye una dificultad diagnóstica en estos pacientes que requieren tratamiento temprano con el fin de evitar complicaciones. El caso es de alta importancia para la comunidad médica, dado que se realiza una revisión del tema, presentación clínica, diagnóstico y manejo de una patología que continúa siendo prevalente.

\section{Reporte de caso}

Paciente masculino de 76 años previamente asintomático y sin enfermedades de base que asiste a consulta externa de urología refiriendo aumento del contenido escrotal. Al examen físico presenta hidrocele bilateral, de predominio derecho, testículos bilaterales normotróficos sin masas, próstata de consistencia aumentada, no dolorosa. Se indica realizar hidrocelectomía y se solicita un antígeno prostático específico (PSA). Posteriormente acude a urgencias por supuración en hemiescroto derecho, asociado a fiebre, pérdida de peso y dolor testicular que no mejoró con manejo antibiótico ambulatorio. Se realiza examen físico al paciente, comprobándose su regular estado general; presenta taquicardia, deshidratación y carencia de áreas de drenaje escrotal, sin zonas crepitantes o de necrosis. Se inicia manejo antibiótico intravenoso y se solicitan paraclínicos, evidenciando leucocitosis con neutrofilia, uroanálisis con piuria estéril y elevación de azoados. La ecografía testicular no presenta hallazgos sugestivos 
de colecciones a nivel escrotal, por lo que se descarta el diagnóstico de absceso escrotal. Por el cuadro infeccioso a nivel escrotal se decide realizar hidrocelectomía derecha, evidenciando drenaje de aproximadamente 100 cc de líquido cetrino con epidídimo derecho engrosado caliente al tacto, el cual se punciona y drena material caseoso y purulento. Testículo derecho indurado sin áreas evidentes de secreción, por lo que se decide realizar epididimectomía derecha (Figura 1). Por hallazgos intraoperatorios de material caseoso y purulento, testículo indurado y sin foco infeccioso aparente, se sospecha tuberculosis genital, se solicitan estudios de patología y baciloscopia seriada para identificar bacilos ácido- alcohol resistente (BAAR). Se da egreso médico por adecuada evolución posoperatoria y control prioritario. El paciente consulta a urgencias a los 5 días posoperatorios con dificultad respiratoria y fiebre. Se encuentra al paciente en mal estado general, taquipneico y desaturado (saturación de oxígeno al ambiente: $85 \%$ ), requiriendo soporte ventilatorio con Venturi. La radiografía de tórax evidencia opacidades micronodulares en todo el parénquima pulmonar. Los reportes de patología y baciloscopia (BK) de epidídimo son positivos para infección por BAAR en tejido por Mycobacterium tuberculosis. Se inicia manejo tetraconjugado (Pirazinamida $1600 \mathrm{mg} /$ día vía oral + Etambutol $1100 \mathrm{mg} /$ día vía oral + Isoniacida $300 \mathrm{mg} /$ día vía oral + Rifampicina $600 \mathrm{mg} /$ día vía oral) asociado a Piridoxina $50 \mathrm{mg}$ /día vía oral, por tuberculosis miliar, pulmonar y genitourinaria. Se decide solicitar ecografía de vías urinarias por la sospecha de TBCGU, evidenciando hallazgos sugestivos de dilatación pielocalicial bilateral, por lo que se solicita urografía excretora para descartar compromiso ureteral. Se evidencia retardo en la eliminación del medio de contraste bilateral asociado a dilatación ureteral bilateral de predominio derecho (Figura 2). Con estos hallazgos sugestivos de TBCGU, se realiza pielografía retrógrada bilateral (Figura 3), y por sus hallazgos se decide derivar al paciente con catéter JJ bilateral por compromiso ureteral de $\mathrm{TBC}$ con el fin de aliviar la dilatación pielocalicial previamente referida y evitar la progresión a falla renal. El paciente es dado de alta por infectología y urología. En el momento se encuentra asintomático con adecuados niveles de azoados.
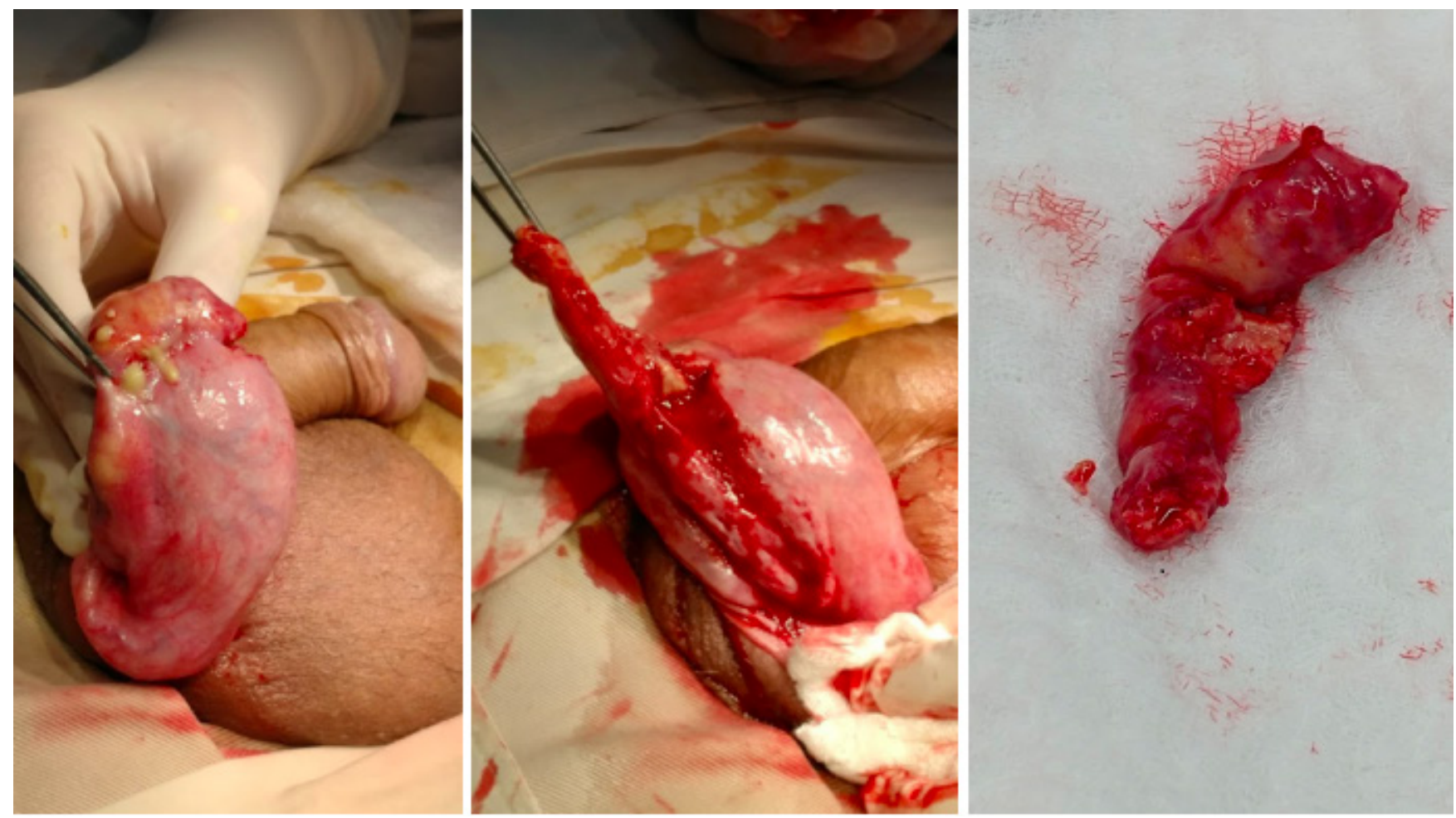

Figura 1. Hallazgos intraoperatorios de hidrocelectomía y epididimectomía derecha. Epidídimo derecho engrosado y caliente al tacto, que se punciona y drena material caseoso y purulento. Testículo derecho indurado sin áreas evidentes de secreción. 


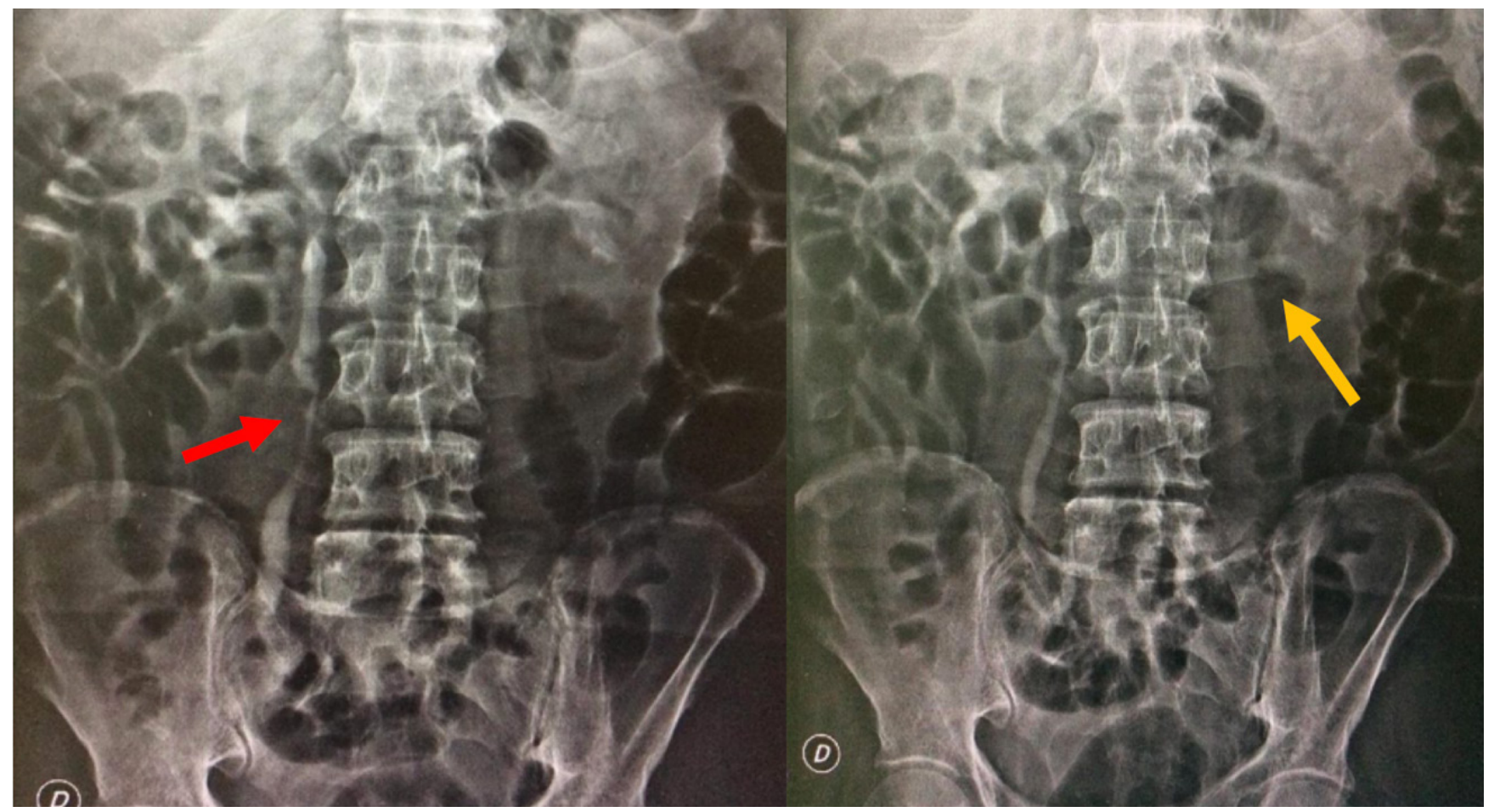

Figura 2. Urografía excretora. Dilatación ureteral bilateral de predominio derecho (flecha roja). Se sugiere retardo en la eliminación del medio de contraste bilateral (flecha amarilla).
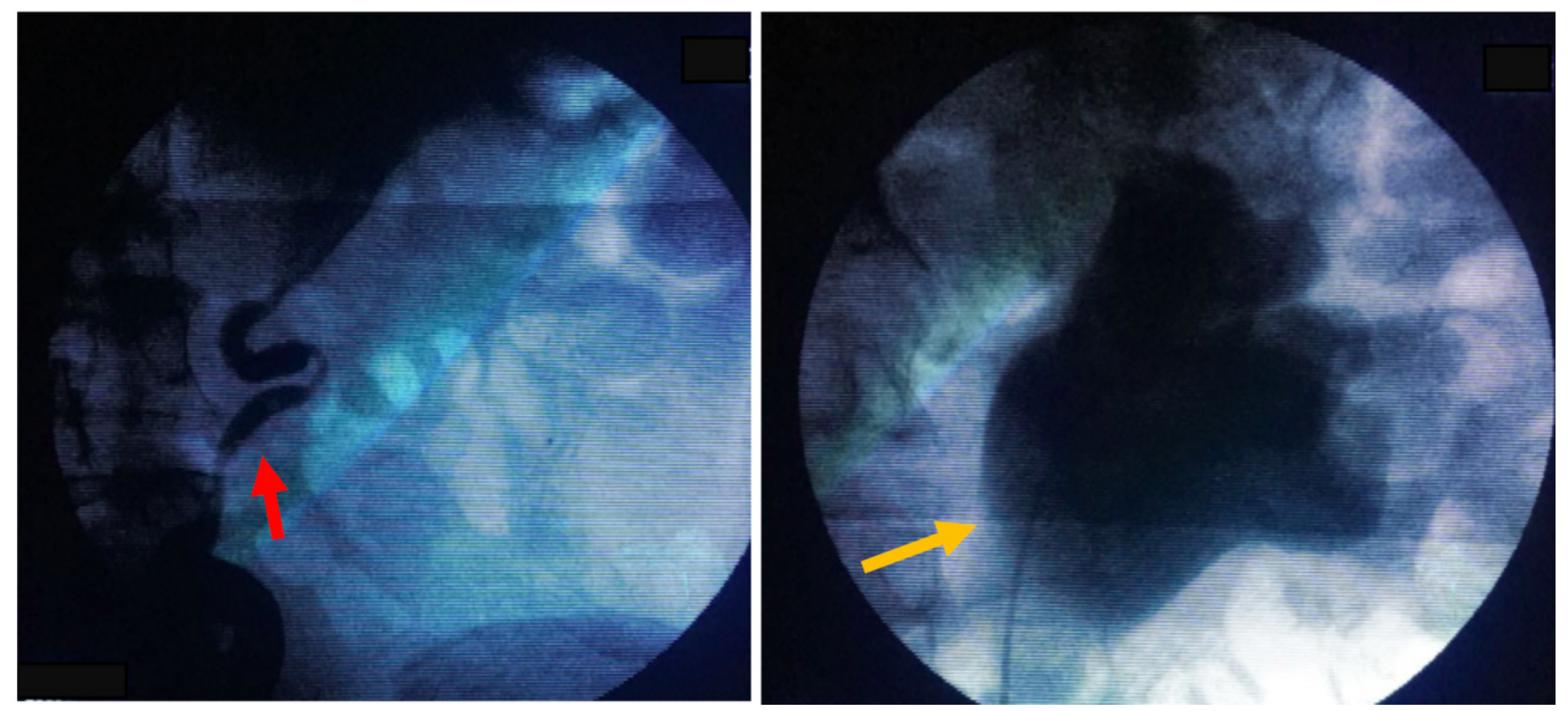

Figura 3. Pielografía retrógrada izquierda. Se confirman los hallazgos de la urografía intravenosa. Dilatación ureteral con múltiples zonas de estrechez (flecha roja). Dilatación pielocalicial (flecha amarilla). 


\section{Discusión}

El SGU es el segundo sitio de mayor afectación de la TBC después del pulmón. Puede afectar los riñones, próstata, vesículas seminales, epidídimo, testículos, pene y uretra $(6,7)$. Se asocia a una alta tasa de morbimortalidad secundaria a infertilidad y falla renal al comprometer los órganos reproductivos $(3,6,8)$. La primera descripción de TBCGU fue realizada por Porter (3) en 1894 y en 1837 Wildbolz (7) sugirió el término de tuberculosis genitourinaria. La TBC extrapulmonar generalmente no es contagiosa. Sin embargo, su identificación y tratamiento tempranos son esenciales para prevenir la diseminación pulmonar subsecuente (dado que más del $50 \%$ de los pacientes con TBCGU presentan TBC pulmonar de manera concomitante), la transmisión y la comorbilidad asociada, incluyendo la falla renal y la infertilidad secundarias $(1,9)$. Zachoval et al. (8) determinaron que un número significativo de pacientes con TBC pulmonar pueden presentar TBCGU subclínica simultáneamente y solo del $5 \%$ al $30 \%$ de los casos comprometen un único órgano $(3,6,8)$. El órgano urinario más frecuentemente afectado es el riñón (cerca del $80 \%)$ y el genital es el epidídimo (22 - $55 \%$ ) (6).

La TBCGU es más común en hombres entre los 30 y 50 años $(6,9)$. La principal vía de diseminación es la hematógena y linfática (3). Generalmente la próstata y el epidídimo son infectados por vía hematógena, mientras que los otros órganos son infectados por la presencia del bacilo en la vía urinaria o por contigüidad con otros órganos $(6,10)$. La sintomatología por TBCGU es inespecífica, por lo que debe sospecharse en pacientes con síntomas urinarios de larga data sin causa aparente, principalmente en población de alto riesgo como la que padece algún grado de inmunosupresión o antecedente de TBC pulmonar (6). El $80 \%$ de los pacientes presenta dolor en flancos, disuria $(54 \%)$, cólico renal (24\%), y hematuria macroscópica $(20 \%)$. El paciente referido en el presente artículo no presentó ninguno de los anteriores síntomas. La TBC genital se manifiesta principalmente con compromiso del epidídimo (48 \%), como la primera o única manifestación. Además, el $45 \%$ de las orquiepididimitis tuberculosas tiene compromiso únicamente del epidídimo y posteriormente presenta compromiso testicular, lo que indica progresión de la enfermedad $(3,11)$. La epididimitis tuberculosa es causada por extensión retrógrada desde la próstata y vesículas seminales o por diseminación hematógena; además, puede ser unilateral o bilateral (12). La cola del epidídimo es la región más comúnmente afectada debido a su alta vascularización, al igual que la corteza renal $(6,9,13)$. Usualmente, la epididimitis bilateral se presenta en un $34 \%$ de los casos, y es secundaria a una
TBC prostática, mientras que la epididimitis unilateral es un hallazgo histológico incidental que ocurre en el 22 $\%$ de los pacientes llevados a cirugía por epididimitis aguda (7), como en el caso del paciente referido, del cual no se sospechaba que el compromiso escrotal fuera por tuberculosis. Pardo et al. (13) reportaron un caso similar de orquiepididimitis tuberculosa y miliar en un paciente de 23 años sin antecedentes de inmunosupresión.

Las manifestaciones clínicas de la epidídimo-orquitis tuberculosa incluyen sensación de masa escrotal (80 \%) que puede ser dolorosa (40 - $44 \%$ ), síndrome miccional $(8 \%)$ y descarga uretral (4\%) (14). El compromiso bilateral se manifiesta con abscesos o fístulas (5 - 10 $\%$ ), y puede estar asociado a hidrocele (6). Este tipo de afección tuberculosa debe sospecharse en pacientes que se presentan con masa escrotal, aunque es difícil diferenciar en el preoperatorio si se trata o no de enfermedad tuberculosa, por lo que es la histopatología la que finalmente confirma el diagnóstico (14). Barandica et al. (10) reportaron también un caso similar al acá documentado, que se presentó como una masa dolorosa a nivel testicular.

En algunos casos, la infertilidad puede ser el primer síntoma debido a la obstrucción de los conductos eyaculadores, lo que lleva a oligoazoospermia (15). De igual forma, la TBC testicular se manifiesta secundaria a epididimitis tuberculosa debido a diseminación hematógena y a la alta vascularización del epidídimo (7). Generalmente, el $62 \%$ de los pacientes con orquiepididimitis son diagnosticados con TBC renal $\mathrm{y}$ en muchos casos los órganos escrotales son los primeros afectados, siendo el único signo en manifiesto de la TBC $(7,14)$, como fue el caso de este paciente. En el examen físico puede manifestarse hidrocele de crecimiento rápido $\mathrm{y}$ doloroso, fístulas escrotales $\mathrm{o}$ perineales y palparse el epidídimo engrosado, indurado y doloroso, con o sin nódulos $(3,16)$.

Los laboratorios son de gran ayuda diagnóstica: cerca del 90 - $100 \%$ de los pacientes con TBC renal presentan leucocituria sin piuria (17). Se pueden evidenciar cavernas tuberculosas en pielografías intravenosas (3).

El estándar para el diagnóstico de TBC se realiza por medio de la identificación y cultivo del bacilo Mycobacterium tuberculosis principalmente de orina en los casos en los que se sospecha TBCGU. Generalmente la piuria estéril en el examen microscópico de orina es un hallazgo clásico de la TBCGU, aunque la hematuria microscópica y macroscópica también pueden encontrarse. La tinción con Ziehl-Neelsen puede identificar bacilos tuberculosos con una sensibilidad 
del $37.1 \%$ al $52.1 \%$; el cultivo tiene una sensibilidad variable de entre $10.7 \%$ al $80 \%$ y su resultado puede tardar de 6 a 8 semanas. La cadena de reacción de polimerasa en pruebas de orina tiene sensibilidad del $94.3 \%$ al $95.6 \%$, y especificidad de $85.7-94.3 \%$. Sin embargo, tiene la desventaja de que no permite diferenciar entre una infección activa o latente. En cuanto a estudios imagenológicos, la ultrasonografía renal no aporta suficiente evidencia sobre TBCGU. Sin embargo, la ultrasonografía de alta resolución es la modalidad de imagen de elección para evaluar a los pacientes que presentan sensación de masa a nivel escrotal o dolor escrotal (6).

Es de vital importancia descartar tumores testiculares e identificarque generalmente la infección por tuberculosis empieza en el epidídimo, y que se extiende al testículo de forma tardía. La epididimitis tuberculosa se presenta como un epidídimo alargado con lesiones nodulares heterogéneas e hipoecoicas. Las imágenes radiológicas no serán útiles en estadios tempranos $(3,9,18)$. Hallazgos ecográficos de orquitis incluyen testículos hipoecoicos homogéneos o heterogéneos, o testículos alargados nodulares heterogéneos e hipoecoicos. Otros hallazgos incluyen engrosamiento de la piel escrotal, hidrocele, abscesos escrotales y fístulas (9). Por lo tanto, una lesión testicular asociada a compromiso del epidídimo y engrosamiento de la piel favorece el diagnóstico de TBCGU (6). La pielografía intravenosa está indicada en pacientes con leucocituria y anormalidades en estudios ecográficos, como en el paciente documentado, que tenía dilatación pielocalicial. La urografía excretora puede detectar signos como distorsión de los cálices, calcificaciones, estenosis de uréter y fibrosis vesical (19), como los evidenciados en este caso.

En cuanto a su manejo, la terapia antituberculosa continúa siendo la primera línea de tratamiento en todas las formas de TBCGU. La mayoría de pacientes inicia con una fase intensiva de tetraconjugado (rifampicina $10 / \mathrm{mg} / \mathrm{kg} /$ día + isoniazida $5 \mathrm{mg} / \mathrm{kg} /$ día + pirazinamida $30 \mathrm{mg} / \mathrm{kg} / \mathrm{día}$ + etambutol $20 \mathrm{mg} / \mathrm{kg} /$ día por 2 meses) y luego con una fase de continuación con 2 medicamentos antituberculosos (isoniazida $5 \mathrm{mg} / \mathrm{kg} /$ día y rifampicina $10 \mathrm{mg} / \mathrm{kg} /$ día por 4 meses) (20). El manejo quirúrgico para la TBCGU está indicado en casos de compromiso extenso que no responden a la terapia antituberculosa ante el diagnóstico de riñón no funcional y excluido, sobreinfección bacteriana asociada, e hipertensión arterial secundaria severa en pacientes monorrenos. El manejo quirúrgico puede incluir desde nefrectomía parcial, nefrectomía total, o hasta cirugía reconstructiva en caso de compromiso ureteral, con el fin de preservar la función renal (21). Aunque la mayoría de los casos con epidídimo-orquitis tuberculosa responden a terapia médica, los abscesos pueden requerir drenaje quirúrgico o percutáneo, como lo requirió el paciente en quien se realizó epididimectomía con el fin de erradicar el proceso infeccioso. Además, las masas escrotales que no responden al manejo médico o que incrementan de tamaño 3 semanas después de iniciado el tratamiento, deben ser exploradas quirúrgicamente con el fin de descartar malignidad testicular $(6,21)$.

\section{Conclusiones}

La TBCGU es una causa común de compromiso extrapulmonar de TBC; entidad en la cual poco se sospecha a pesar del alto número de pacientes diagnosticados al año. Su diagnóstico y tratamiento oportuno serán de gran importancia, principalmente en población de riesgo como inmunosuprimidos o con antecedente de TBC pulmonar.

\section{Financiación}

Ninguna

\section{Conflictos de Interés:}

Los autores declaran no tener conflictos de interés.

\section{Consideraciones éticas:}

Para la publicación de este artículo se contó con la autorización del paciente por medio del consentimiento informado autorizando la manipulación de los datos con fines académicos e investigativos según la resolución 8430 de 1993.

\section{Referencias}

1. Chang AH, Blackburn B, Hsieh M. Tuberculosis and Parasitic Infections of the Genitourinary Tract. En: Campbell-Walsh urology. 11th ed. Elsevier; 2016. p. 421-446.e5.

2. WHO. Global tuberculosis report 2017 [Internet]. Report. 2017. Disponible en: https://www.who.int/campaigns/tb-day/2018/exe_summary_es.pdf?ua=

3. Kulchavenya E, Naber K, Bjerklund Johansen TE. Urogenital Tuberculosis: Classification, Diagnosis, and Treatment. Eur Urol Suppl. 2016;15(4):112-21.

4. Instituto nacional de S. Informe del Evento: Tuber- 
culosis Colombia 2017 [Internet]. 2017 [cited 2003 Sep 20]. Disponible en: https://www.ins.gov.co/ buscadoreventos/Informesdeevento/Tuberculosis 2017.p\%0D\%0Adf\%0D\%0A

5. Díaz ML, Muñoz S, Garcíad LB. Tuberculosis en el Hospital Universitario San José, Popayán, 1998-2000. Biomédica. 2014;24(0):92.

6. Yadav S, Singh P, Hemal A, Kumar R. Genital tuberculosis: current status of diagnosis and management. Traducción de Androl Urol [Internet]. 2017;6(2):22233. Disponible en: http://tau.amegroups.com/article/ view/13854/14808

7. Kulchavenya E. Urogenital tuberculosis: Definition and classification. Ther Adv Infect Dis. 2014;2(6):11722.

8. Zachoval R, Nencka P, Vasakova M, Kopecka E, Borovička $\mathrm{V}$, Wallenfels $\mathrm{J}$, et al. The incidence of subclinical forms of urogenital tuberculosis in patients with pulmonary tuberculosis. J Infect Public Health. 2017; 11:243-5.

9. Woldenberg N, Patel MK, Hansen G. Tuberculous epididymitis a case of tuberculous epididymitis that was the presenting manifestation of extrapulmonary and pulmonary tuberculoses. Ultrasound Q. 2015;31(3):192-4.

10. Barandica L, Cabrera B, Cuadrado BS. Tuberculosis Testicular: Reporte de un Caso Testicular Tuberculosis: Case Report. Urol Colomb [Internet]. 2017;38. Disponible en: https://www.thieme-connect.com/ products/ejournals/abstract/10.1055/s-0038-1648212

11. Passos MRL, Ferreira DC, Arze WNC, Silva JCS, Passos FDL, Curvelo JAR. Penile myiasis as a differential diagnosis for genital ulcer: a case report. Braz $\mathbf{J}$ Infect Dis. 2008;12(2):155-7.

12. Mantilla Hernández JC, Cárdenas Durán N, Castellanos Bustos DA. Tuberculosis genitourinaria: Reporte. Salud UIS. 2008; 41:2009.

13. Pardo L, Gutiérrez C, Carrillo Bayona J, Polo Nieto F. Tuberculosis miliar y orquiepididimitis tuberculosa en un paciente inmunocompetente: reporte de caso. Urol Colomb [Internet]. 2018;38. Disponible en: https:// www.thieme-connect.com/products/ejournals/pdf/10.1055/s-0038-1648212.pdf
14. Kulchavenya E. Urogenital Tuberculosis: Epidemiology, Diagnosis, Therapy. Springer; 2014. 146 p.

15. Figueiredo AA, Lucon AM, Srougi M. Urogenital Tuberculosis. Tuberc Nontuberculous Mycobact Infect Seventh Ed [Internet]. 2017;355-70. Disponible en: http://www.asmscience.org/content/ book/10.1128/9781555819866.chap22

16. Gupta B, Shree S, Rajaram S, Goel N. Genital tuberculosis: Unusual presentations. Int J Mycobacteriology [Internet]. 2016;5(3):357-9. Disponible en: http:// dx.doi.org/10.1016/j.ijmyco.2016.06.017

17. Hosamirudsari H, Mohammadizia F. Unilateral tuberculous epididymo-orchitis with scrotal fistula: A case report. Iran J Pathol. 2015;10(2):165-8.

18. García IG, Mampaso EG, Revilla JB, Molina MR, Crespo AS, Buitrago LA, et al. Tuberculous orchiepididymitis during 1978-2003 period: Review of 34 cases and role of 16SrRNA amplification. Urology [Internet]. 2010;76(4):776-81. Disponible en: http:// dx.doi.org/10.1016/j.urology.2010.01.033

19. Castro-Duarte Juan Carlos, López-Alarcón Alejandro, Villegas-Capiz Jorge V-CMA. Tuberculosis genitourinaria - Editorial Elsevier. Rev Mex Urol [Internet]. 2011;71(81):18-21. Available from: http://www.elsevier.es/es/revistas/revista-mexicana-urologia-302/ tuberculosis-genitourinaria-90000960-casos-clinicos-2011

20. Protección Social M. Guía de atención de la tuberculosis pulmonar y extrapulmonar. Guías de promoción de la salud y prevención de enfermedades en la salud pública. 2015.

21. Abbara A, Davidson RN. Etiology and management of genitourinary tuberculosis. Nat Rev Urol [Internet]. 2011;8(12):678-88. Disponible en: http://dx.doi. org/10.1038/nrurol.2011.172 